\title{
ANTI-INFLAMMATORY AND ANTI-GRANULOMA ACTIVITY OF SULFORAPHANE, A NATURALLY OCCURRING ISOTHIOCYANATE FROM BROCCOLI (BRASSICA OLERACEA)
}

\author{
SANGEETA MOHANTY ${ }^{1 *}$, ABHISEK PAL ${ }^{1}$, V BADIREENATH KONKIMALLA ${ }^{2}$, SUDAM CHANDRA SI ${ }^{1}$
}

\begin{abstract}
${ }^{1}$ Department of Pharmaceutics, School of Pharmaceutical Sciences, Siksha 0 Anusandhan Deemed to be University, Bhubaneswar, India. ${ }^{2}$ Department of Biology, School of Biological Sciences, National Institute of Science Education and Research, Bhubaneswar, Odisha, India. Email: sangeetamohanty@soauniversity.ac.in
\end{abstract}

Received: 14 February 2018, Revised and Accepted: 26 March 2018

ABSTRACT

Objective: The objective of this study was to establish the anti-inflammatory activity of sulforaphane (SFN) in different acute and subchronic models of inflammation.

Methods: The anti-inflammatory activity of SFN was evaluated by the secretion of proinflammatory cytokines in rat peripheral blood mononuclear cells (interleukin-6 [IL-6] and tumor necrosis factor alpha [TNF- $\alpha$ ]) which are important mediators of inflammation as determined by enzyme-linked immunosorbent assay. Furthermore, paw volume was determined in various acute models of inflammation, and percentage inhibition of granuloma tissue was assessed by cotton pellet-induced granuloma model. From serum, serum glutamic pyruvic transaminase, serum glutamic oxaloacetic transaminase, and alkaline phosphatase levels were determined which is followed by assay for estimation of antioxidants such as superoxide dismutase (SOD), catalase, and glutathione (GSH).

Results: SFN showed significant anti-inflammatory activity against paw edema induced by carrageenin/histamine/egg-albumin. A remarkable control in inflammation was observed most notably at the highest test dose of $5 \mathrm{mg} / \mathrm{kg}$ in the subchronic granuloma model. In addition, the release of inflammatory cytokines such as IL- 6 and TNF- $\alpha$ which is responsible for inflammatory activity gets attenuated by SFN $(* \mathrm{p}<0.05 ; * * \mathrm{p}<0.01)$. Moreover, toxic control rats showed significant decreased levels of GSH, catalase, and SOD and increased the level of serum hepatic enzymes which gets reversed by SFN in dose-dependent manner.

Conclusions: The present findings demonstrated that SFN can recover inflammation by inhibiting TNF- $\alpha$ and IL-6 in inflammation process.

Keywords: Sulforaphane, Inflammation, Cytokine, Anti-inflammatory.

(c) 2018 The Authors. Published by Innovare Academic Sciences Pvt Ltd. This is an open access article under the CC BY license (http://creativecommons. org/licenses/by/4. 0/) DOI: http://dx.doi.org/10.22159/ajpcr.2018.v11i6.25279

\section{INTRODUCTION}

For humankind, the word "Inflammation" is always proved to be an enigma in terms of understanding. However, starting from a minor bruise to a major myocardial infarction is just sufficient to trigger this phenomenon. Inflammation and pain are the common nonspecific manifestations of many diseases. It is a defense mechanism aimed to remove the injurious stimuli and initiates the tissue healing process [1]. Inflammatory processes are complex biochemical phenomena characterized by tissue edema, pain, and leukocyte infiltration [2]. The cardinal signs of inflammation are pain, edema, loss of function, redness, and heat [3]. Various endogenous mediators such as histamine, serotonin, bradykinin, and prostaglandins are most abundant in inflammatory cells [4]. However, prolonged inflammation can lead to numerous diseases including rheumatoid arthritis, psoriasis, and inflammatory bowel disease. Due to the complex etiology of inflammation, identification of effective therapies has proven difficult. Although many of drugs used for the treatment, transiently suppress symptoms and ameliorate inflammation are not helpful in significantly treating the disease in the long term. But it results in serious side effects as in case of nonsteroidal anti-inflammatory drugs, analgesics, glucocorticoids, and disease-modifying antirheumatic drugs.

Treatments targeting cytokines, including antitumor necrosis factor alpha (TNF- $\alpha$ ) antibodies, soluble TNF receptor, anti-interleukin receptor antibody, and IL-1 receptor antagonist, are widely used in addition to DMARDs and anti-inflammatory agents, but due to its high cost and increased susceptibility of patients to infection, made it less effective therapy [5-7]. Therefore, newer drugs with low or no toxicity for the treatment of subchronic inflammation are actively being sought. Looking at the present scenario, there is dramatically growing interest in herbal medicines, and the use of complementary and alternative medicines among persons for chronic conditions, has increased in recent years [8-10].

Compound obtained from plants provides a remarkable role to cure and control various diseases from ancient times. About $80 \%$ of the population relies on traditional medicine as per a surveillance conducted by the World Health Organization. Numerous studies have been conducted and validated the secondary metabolites present in the plants imparts pharmacological activity to combat numerous diseases $[11,12]$. Plant containing isothiocyanate (ITC) is a good choice to use as anti-inflammatory drugs.

Sulforaphane (SFN) 1-isothiocyanato-4-(methylsulfinyl-butane), a naturally occurring ITC, and biologically active metabolite of glucoraphanin which is metabolized by the enzyme myrosinase obtained through the consumption of cruciferous vegetables such as broccoli, brussels sprouts, and cabbage is one of the most potent inducers of phase 2 enzymes [13]. SFN has been known to have a variety of properties including anticarcinogenic and antimicrobial properties in experimental models [14,15]. It inhibits cytokine production in preclinical and clinical studies and is an indirect longacting antioxidant [16]. SFN has been shown in laboratory studies with mice to switch on a protective protein ( $\mathrm{Nrf} 2)$ that helps to prevent the atherosclerotic buildup of plaques in arterial walls [17]. 
Such properties are a prerequisite for an anti-inflammatory drug. However, all these mechanistic studies performed are in cell line (in vitro), and no scientific reports are available on anti-inflammatory effects of SFN in rat peripheral blood mononuclear cells (PBMCs). Hence, the present work was undertaken to investigate the antiinflammatory and anti-granuloma potential of SFN (in vivo) on different acute and subchronic rat models as a preclinical study.

\section{METHODS}

\section{Animals}

Adult albino Wistar rats and Swiss albino mice of either sex weighing between 180 and 200 and 20-30 g, respectively, were used for the study. The animals were housed in well-ventilated cages in an air-conditioned animal house with a $12 \mathrm{~h}$ light and dark control conditions. The animals were fed with standard pellet diet and water ad libitum. Before experiments, the procedure and protocols used in the study were approved by Institutional Animal Ethical Committee (Approval number. 03/16/IAEC/SPS/SOAU) under School of Pharmaceutical Sciences, SOA University. Bhubaneswar, India, in accordance with the Committee for the purpose of Control and Supervision of Experiments on Animals (CPCSEA), guidelines, Chennai, India.

\section{Drugs and reagents}

D, L-Sulforaphane (CAS Number: 142825-10-3, purity >98\%) was purchased from Sigma-Aldrich Chemical Co., USA. Analytical grades of dimethylsulfoxide were procured from Merck Chemicals, Mumbai. Carrageenan, histamine, and egg-albumin were purchased from SigmaAldrich Chemical Co., USA. Rat interleukin-6 [IL-6] and TNF- $\alpha$, enzymelinked immunosorbent assay (ELISA) kits were purchased from $\mathrm{R}$ to D Systems (Minneapolis, MN). All other chemicals used in the present study were of analytical grade.

\section{Experimental set up}

The animals were randomly divided into five groups, each group containing six animals $(n=6)$. In case of acute inflammatory models (i.e., carrageenan-induced rat paw edema model/histamine-induced rat paw edema model/egg-albumin-induced rat paw edema model), the animals were treated for $0-6 \mathrm{~h}$ (in a single day). In case of subchronic inflammatory model (cotton pellet-induced granuloma model), each group was treated with cotton pellet granuloma for 15 days (Fig. 1a and b).

\section{Acute toxicity studies}

The oral toxicity studies were carried out as per the guideline set by the Organization for Economic Cooperation and Development (OECD guidelines 423 ) received from the CPCSEA. Swiss albino mice $(n=6)$ of either sex selected by random sampling were used for acute toxicity studies [18]. The animals were kept fasting overnight and provided only with water, after which the drugs were administered orally at $1 \mathrm{mg} / \mathrm{kg}$ body weight by gastric intubations and observed for 14 days. If mortality was observed in two out of three animals, then the dose administered was considered as toxic dose. In case, mortality was observed in one animal; then, the same dose was repeated again to confirm the dose. However, if no mortality was observed, the same procedure was repeated for higher doses such as 20,30, 50, and $100 \mathrm{mg} / \mathrm{kg}$ body weight.

\section{ACUTE INFLAMMATORY MODELS}

\section{Carrageenan-induced rat paw edema model}

The rats were divided into five groups $(\mathrm{n}=6)$ each receiving distilled water (control), Diclofenac $10 \mathrm{mg} / \mathrm{kg}$ p.o. (reference standard), and SFN ( $2 \mathrm{mg} / \mathrm{kg}$ p.o. and $5 \mathrm{mg} / \mathrm{kg}$ p.o. dose), respectively. Carrageenan $(0.1 \mathrm{~mL}$ of $1 \%)$ was injected into the subplantar tissue of the right hind paw of each rat. The volume of the carrageenan injected into the foot was measured at $0,1^{\text {st }}, 3^{\text {rd }}$, and $6^{\text {th }} \mathrm{h}$ using a plethysmometer (Biodevices, New Delhi, India). The paw volume at each time interval was measured [19].

\section{Histamine-induced rat paw edema model}

The rats were divided into five groups $(n=6)$ each receiving distilled water (control), Diclofenac $10 \mathrm{mg} / \mathrm{kg}$ p.o. (reference standard), and SFN $(2 \mathrm{mg} / \mathrm{kg}$ p.o. and $5 \mathrm{mg} / \mathrm{kg}$ p.o. dose), respectively. Histamine $(0.1 \mathrm{~mL}$ of 1\%) was injected into the subplantar tissue of the right hind paw of each rat. The volume of the histamine injected into the foot was measured at $0,1^{\text {st }}, 3^{\text {rd }}$, and $6^{\text {th }} \mathrm{h}$ using a plethysmometer (Biodevices, New Delhi, India). The paw volume at each time interval was measured [19].

\section{Egg-albumin-induced rat paw edema model}

The rats were divided into five groups (six in each group), each receiving distilled water (control), Diclofenac $10 \mathrm{mg} / \mathrm{kg}$ p.o. (reference standard), and SFN ( $2 \mathrm{mg} / \mathrm{kg}$ and $5 \mathrm{mg} / \mathrm{kg}$ p.o. dose), respectively. Eggalbumin $(0.1 \mathrm{~mL}$ of $1 \%)$ was injected into the subplantar tissue of the right hind paw of each rat. The volume of the egg-albumin injected into the foot was measured at $0,1^{\text {st }}, 3^{\text {rd }}$, and $6^{\text {th }} \mathrm{h}$ using a plethysmometer (Biodevices, New Delhi, India). The paw volume at each time interval was measured [19].

\section{Subacute toxicity \\ Cotton pellet-induced granuloma model}

The rats were divided into five groups $(\mathrm{n}=6)$, each receiving distilled water (control), Diclofenac $10 \mathrm{mg} / \mathrm{kg}$ p.o. (reference standard), and SFN $(2 \mathrm{mg} / \mathrm{kg}$ and $5 \mathrm{mg} / \mathrm{kg}$ p.o. dose), respectively. $30 \mathrm{~min}$ after drug administration, the rats were anesthetized with ether. An autoclaved cotton pellet $(10 \pm 1.0 \mathrm{mg})$ was aseptically implanted subcutaneously in the back region of the rats. Drugs (i.e., SFN and standard Diclofenac sodium) were administered once daily for the next 14 days. On day 15, animals were anesthetized again, and cotton pellets (Datt Mediproducts Ltd., New Delhi, India) were removed surgically, freed from the extraneous tissue, and dried in a hot-air oven overnight at $60^{\circ} \mathrm{C}$. The dried pellets were weighed and the increase in the dry weight of the pellets was taken as a measure of granuloma formation.

The PI of granuloma tissue development was calculated: [19]

$\mathrm{PI}=$ Weight of pellet (control) -weight of pellet (test)/Weight of pellet (control) $\times 100$

\section{Serum IL-6 and TNF- $\alpha$ assay}

On day 15 , the toxicant, i.e., cotton pellet-induced granuloma rats were anesthetized with diethyl ether $24 \mathrm{~h}$ after the last administration of drug and standard diclofenac sodium. By abdominal aortic method, blood samples were collected and were allowed to stand for $30 \mathrm{~min}$. Serum was collected by centrifugation at $1000 \mathrm{rpm}$ for $15 \mathrm{~min}$. The concentrations of IL- 6 and TNF- $\alpha$ in serum were measured by sandwich ELISA using commercially available reagents according to the manufacturer's instruction. The absorbance was measured at $570 \mathrm{~nm}$ on a microplate reader. The levels of IL- 6 and TNF- $\alpha$ were expressed as picograms per milliliter of serum based on the appropriate standard curve.

\section{Isolation of PBMCs}

Rat peripheral blood was obtained from both treated (granulomainduced rats, i.e., Group-II, III, IV, and V) and untreated rats (Group-I normal rats) and kept in sterile sodium heparin tubes. The blood samples were added with phosphate buffer saline (PBS) (pH-7.4) and Ficoll-Paque ${ }^{\text {TM }}$ PLUS (GE Healthcare) to obtain PBMCs. The heparin zed bloods were then centrifuged at $2000 \mathrm{rpm}$ for $20 \mathrm{~min}$, at a temperature of $15^{\circ} \mathrm{C}$, to obtain $\mathrm{PBMC}$ ring. The obtained PBMC (in ring form) was then centrifuged by mixing it with PBS and Fetal bovine serum (FBS) at $1000 \mathrm{rpm}$ for $20 \mathrm{~min}$ at a temperature of $15^{\circ} \mathrm{C}$ to obtain leukocyte cloud. The PBMC cells from the interphase were extracted and washed 3 times with PBS $\left(10 \mathrm{~min}, 1000 \mathrm{rpm}, 15^{\circ} \mathrm{C}\right)$. Cells were allowed to be cultured in Roswell Park Memorial Institute (RPMI) 1640 medium with $20 \mathrm{~mm}$ Hepes supplemented with $10 \%$ FBS, Hi-Media after the last wash. The number of PBMCs was counted using hemocytometer.

\section{Cell proliferation assays}

Cell proliferation assays were performed using 3-(4,5-dimethyl-2thiazolyl)-2, 5-diphenyl-2H-tetrazolium bromide (MTT) assay kit 


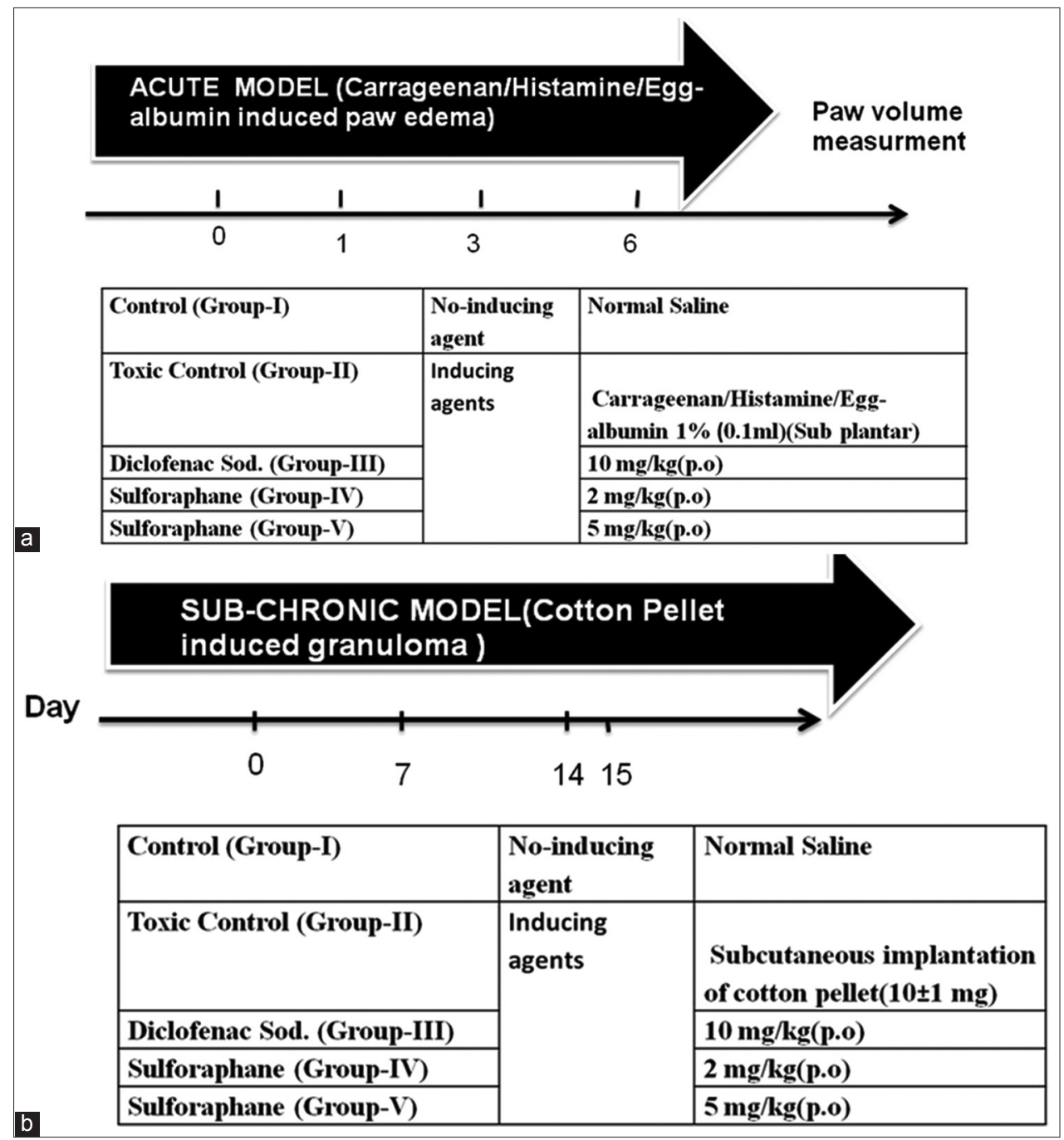

Fig. 1:(a) Experimental design for acute model. (b) Experimental design for sub-chronic model

(e-Bioscience) as per the instruction of the manufacturer. Cultured PBMCs were resuspended $\left(5 \times 10^{6} \mathrm{cell} / \mathrm{s} / \mathrm{ml}\right)$ in RPMI- 1640 medium in the presence of lipopolysaccharide (LPS). Then, $100 \mu \mathrm{l}$ of different concentration of both treated and untreated samples was added in RPMI-1640. Incubation of cultured plates was carried out for $48 \mathrm{~h}$ in a $\mathrm{CO}_{2}$ incubator $\left(5 \% \mathrm{CO}_{2}\right.$ and $37^{\circ} \mathrm{C}$ temperature $)$. After incubation, $10 \mu \mathrm{l}$ of MTT $(2.5 \mathrm{mg} / \mathrm{ml})$ solution was added to each well, and the plates were wrapped to avoid exposure from light. Incubation is allowed for $4 \mathrm{~h} .100 \mu \mathrm{l}$ of the solubilizing reagent was added to each well, and the absorbance was recorded at $570 \mathrm{~nm}$ using Mindray MR-96A microplate absorbance reader.

\section{Estimation of proinflammatory cytokine (IL- 6 and TNF- $\alpha$ )}

Treated PBMCs were cultured in triplicate at a concentration of $5 \times 10^{6}$ cells $/ \mathrm{mL}$ and were added separately in 24 wells cell culture plate. For positive control, LPS $(10 \mathrm{ng} / \mathrm{mL}$ ) was used for stimulation inflammatory cytokine. The control groups of cells were cultured without addition of drug. Plates were kept for incubation in a $\mathrm{CO}_{2}$ incubator $\left(5 \% \mathrm{CO}_{2}\right)$ at $37^{\circ} \mathrm{C}$ for 12,24 , and $48 \mathrm{~h}$ separately. For cytokine production, separate wells were used for harvesting culture supernatants. The culture supernatants were harvested, centrifuged, and stored at $-70^{\circ} \mathrm{C}$ for estimation of cytokine. Later on, cytokine assay was performed using IL- 6 and TNF- $\alpha$ sandwich ELISA kits (e-Bioscience) as per manufacturer's instruction and the absorbance recorded was expressed in picograms per millimeter by interpolation from standard curves [20].
Statistical analysis

All results were expressed as mean \pm standard error of the mean. The significance of differences between treated groups was determined using Dunnett's t-test. One-way analysis of variance is followed by Dunnett's t-test. $p<0.05$ was also considered statistically significant.

\section{RESULTS}

SFN suppresses rat paw volume on carrageenan-induced acute inflammatory model

Group-II animals exhibited a marked peripheral edema of injected paw, subsequently observable after few hours of injection. Administration of SFN (at dose $2 \mathrm{mg} / \mathrm{kg}$ p.o. and $5 \mathrm{mg} / \mathrm{kg}$. p.o.) significantly $(\mathrm{p}<0.05)$ reduced the paw swelling when compared with carrageenan-induced rats. Std. Diclofenac-treated group also shows a notable decrease in paw volume. By drug treatment, the paw swelling in SFN and Diclofenac-treated groups almost reduced to a larger extent (Fig. 2).

SFN suppresses rat paw volume on histamine-induced acute inflammatory model

With the administration of SFN at the dose of $2 \mathrm{mg} / \mathrm{ml}$ and $5 \mathrm{mg} / \mathrm{ml}$, paw volume gets decreased in dose-dependent manner as compared to Group-II. The significant reduction also reflects in std. Diclofenactreated Group III (Fig. 3). 
Values are expressed in mean \pm standard error of the mean from six animals in each group $\left({ }^{*} \mathrm{p}<0.05\right)$. One-way analysis of variance is followed by Dunnett's t-test. Group II is compared with Group I. Group III, IV, and V are compared with Group II. Group I - normal rats, Group II - histamine control, Group III - std. diclofenac $10 \mathrm{mg} / \mathrm{kg}$, Group IV - sulforaphane (SFN) $2 \mathrm{mg} / \mathrm{kg}$, and Group V - SFN 5 mg/kg

SFN suppresses rat paw volume in egg-albumin-induced acute inflammatory model

Rats injected with egg-albumin (Group-II) showed a significant increase in paw volume when compared with normal rats (Group-I). The SFN treatment at the dose of $2 \mathrm{mg} / \mathrm{ml}$ and $5 \mathrm{mg} / \mathrm{ml}$ showed significant $\left({ }^{*} \mathrm{p}<0.05\right)$ reduction in rat paw vol. as compared to Group-II. The significant reduction also reflects in std. Diclofenac-treated Group III (Fig. 4).

Anti-granuloma effect of SFN in cotton pellet-induced granuloma (subchronic model)

In cotton pellet-induced granuloma, both doses of SFN were found to be effective at the exudatory and granulatory phase of inflammation.

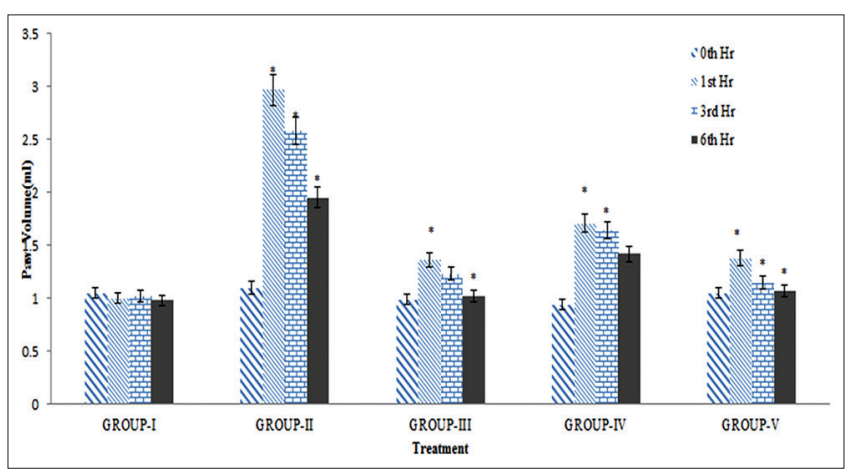

Fig. 2: Effect of sulforaphane on carrageenan-induced hind paw edema in rats. Values are expressed in mean \pm standard error of the mean from six animals in each group $\left({ }^{*} \mathrm{p}<0.05\right)$. One-way analysis of variance is followed by Dunnett's t-test. Group II is compared with Group I. Group III, IV, and V are compared with Group II. Group I - normal rats, Group II - carrageenan control, Group III - std. diclofenac $10 \mathrm{mg} / \mathrm{kg}$, Group IV - sulforaphane (SFN) 2 mg/kg, Group V - SFN 5 mg/kg

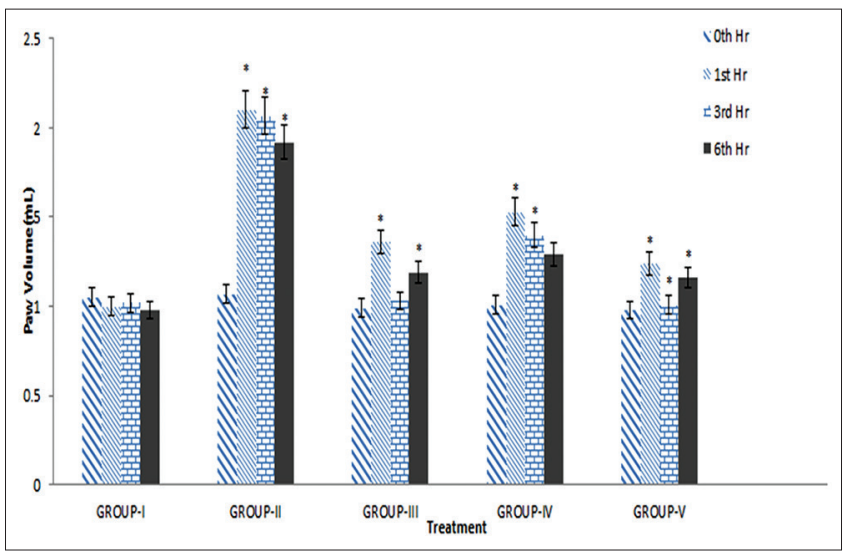

Fig. 3: Effect of Sulforaphane on histamine-induced hind paw edema in rats. Values are expressed in mean \pm standard error of the mean from six animals in each group ( $\left.{ }^{*} \mathbf{p}<0.05\right)$. One-way analysis of variance is followed by Dunnett's t-test. Group II is compared with Group I. Group III, IV, and V are compared with Group II. Group I - normal rats, Group II - histamine control, Group III - std. diclofenac $10 \mathrm{mg} / \mathrm{kg}$, Group IV - sulforaphane (SFN) $2 \mathrm{mg} / \mathrm{kg}$, and Group V - SFN 5 mg/kg
Both, SFN at dose $2 \mathrm{mg} / \mathrm{kg}$ and $5 \mathrm{mg} / \mathrm{kg}$ were found to inhibit exudates formation by 43.99 and $60.41 \%$, respectively, and inhibit granuloma formation by 40.06 and $62.88 \%$, respectively (Table 1 ).

SFN suppresses proinflammatory cytokines IL-6 and TNF- $\alpha$ in cotton pellet-induced rats

The effect of SFN on inflammatory cytokines was investigated in the cotton pellet granuloma model by sandwich ELISA. As shown in Fig. 5a and b, a great majority of proinflammatory cytokines was released from rat PBMC following on induction with cotton pellet granuloma. Treatment with SFN significantly decreased proinflammatory cytokine levels $(\mathrm{p}<0.05, \mathrm{p}<0.01)$ Inhibition rates for IL- 6 and TNF- $\alpha$ at SFN $5 \mathrm{mg} / \mathrm{kg}$ were approximately 16.26 and $40.54 \%$

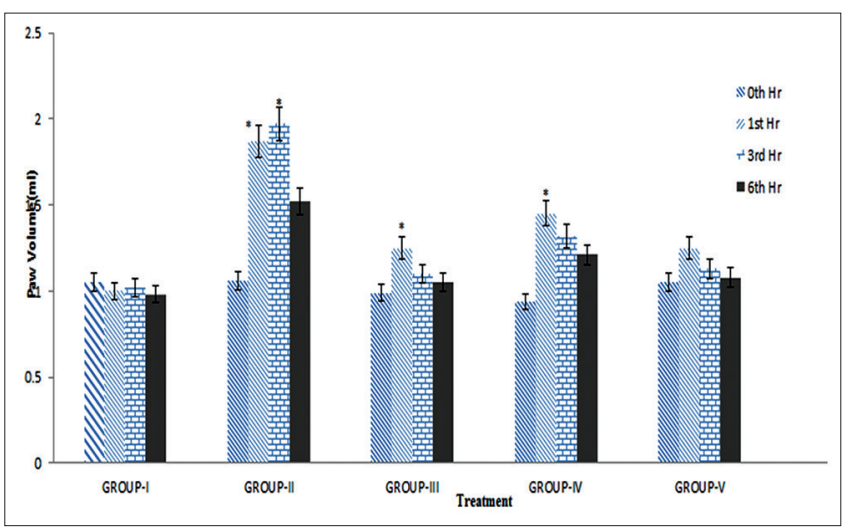

Fig. 4: Effect of Sulforaphane on egg-albumin-induced hind paw edema in rats. Values are expressed in mean \pm standard error of the mean from six animals in each group ( $\left.{ }^{*} p<0.05\right)$. One-way analysis of variance is followed by Dunnett's t-test. Group II is compared with Group I; Group III, IV, and V are compared with Group II. Group I - normal rats, Group II - egg-albumin control),

Group III - std. diclofenac $10 \mathrm{mg} / \mathrm{kg}$, Group IV - sulforaphane

(SFN) $2 \mathrm{mg} / \mathrm{kg}$, and Group V - SFN-5 mg/kg

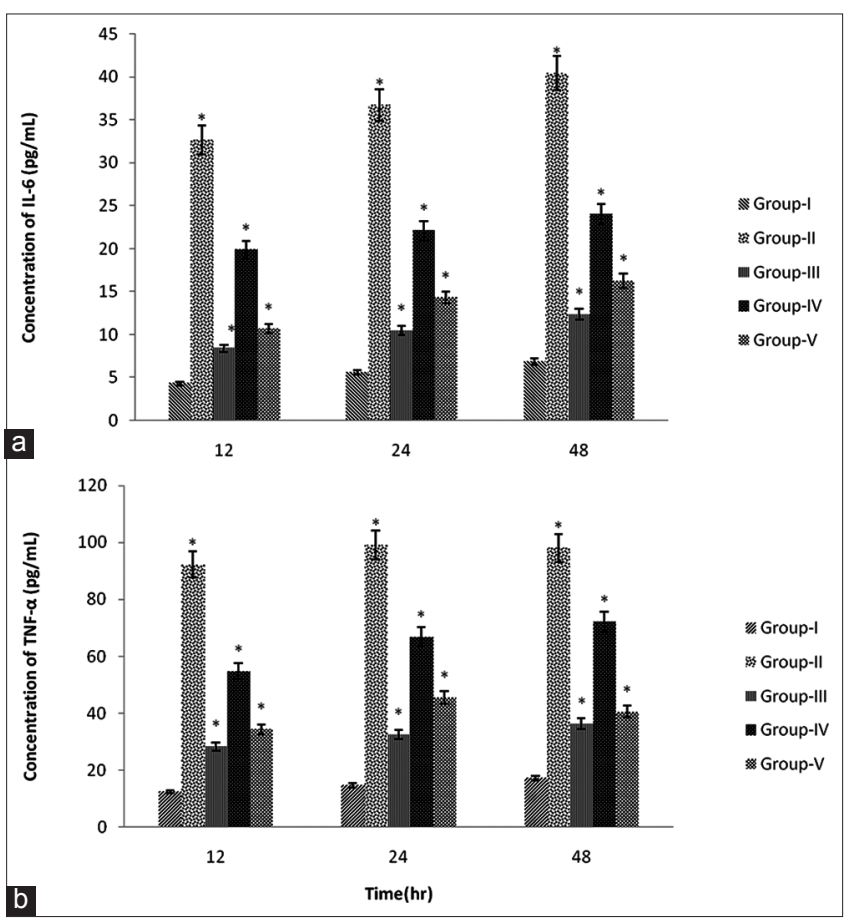

Fig. 5: (a and b) Effect of Sulforaphane on proinflammatory cytokines interleukin- 6 and tumor necrosis factor alpha on cotton pellet-induced granuloma rats 
as against 40.42 and $98.11 \%$ of toxic control group, respectively, at the end of $48 \mathrm{~h}$.

Differential effects of SFN on pro-inflammatory cytokine secretion in rat PBMCs; PBMCs $(5 \times 105 / \mathrm{ml})$ were cultured in the presence of increasing concentrations of proinflammatory cytokines IL-6 and TNF- $\alpha$ (pg/ml) for 12,24 and $48 \mathrm{~h}$. At the end of the culture, the concentrations of IL-6 and TNF- $\alpha$ in the conditioned media were determined using ELISA kits as described in materials and methods. The results are the means \pm SD of six different rats. $* \mathrm{p}<0.05$ and $* * \mathrm{p}<0.01$ as compared with the value in the untreated.

Group I - normal rats, Group II (cotton pellet-induced granuloma), Group III (std. Diclofenac $10 \mathrm{mg} / \mathrm{kg}$ ), Group IV (SFN $2 \mathrm{mg} / \mathrm{kg}$ ), and Group V (SFN 5 mg/kg)

Values are expressed as mean \pm SEM from six animals in each group. Group I - normal rats, Group II (toxicant control rats), Group III (std. Diclofenac $10 \mathrm{mg} / \mathrm{kg}$ ), Group IV (SFN $2 \mathrm{mg} / \mathrm{kg}$ ), and Group V (SFN $5 \mathrm{mg} / \mathrm{kg}$ )

Antioxidant effect of SFN induces anti-inflammatory activity in cotton pellet-induced rats

Results from biochemical assays showed elevated levels (as shown in Table 2) in serum levels for serum glutamic pyruvic transaminase (SGPT), serum glutamic oxaloacetic transaminase (SGOT), and alkaline phosphatase (ALP) in toxic-induced animals (cotton pellet-induced group) $(\mathrm{p}<0.01)$ and reduced levels of oxidative markers superoxide dismutase (SOD), catalase, and glutathione $(\mathrm{GSH})(\mathrm{p}<0.01)$ in comparison to the normal uninduced rats. Contrastingly, the cotton pellet-induced animals treated with SFN at $5 \mathrm{mg} / \mathrm{kg}$ showed a significant alteration in the enzymatic activity and antioxidant activity comparable to standard control and to that of the cotton pellet-uninduced group. This indicates the strong anti-inflammatory potential of SFN to restore the animals to normal condition.

\section{DISCUSSION}

Initiation of inflammatory response in body is either due to cell injury or antigenic reaction, whereas inflammatory signs and symptoms develop due to various chemical mediators such as histamine, serotonin, kinins, ROS (reactive oxygen species), prostaglandins, and leukotrienes [21] Carrageenan-induced edema is a common experimental model for the pharmacological evaluation of anti-inflammatory potential and efficacy of a drug molecule. The injection of carrageenan into the hind paw of rat causes inflammation which is indicated by the cardinal signs of inflammation such as edema, erythema, and hyperalgesia.
The carrageenan-induced inflammation is responsible for the development of pathophysiological three distinct phases of the release of the mediator, including serotonin and histamine in the first phase $(0-2 \mathrm{~h})$, kinins in the second phase $(3 \mathrm{~h})$, and prostaglandin in the third phase ( $>4 \mathrm{~h}$ ) [22]. SFN significantly inhibited paw edema induced by carrageenan in all the three phases in a dose-dependent manner. The anti-edematous response also reflects in standard drug diclofenac sodium treated group. This reflects the mediator's inhibition activity and cyclooxygenase inhibitory property of SFN.

The most important inflammatory mediator histamine is a potent vasodilator substance and is responsible for increased vascular permeability $[23,24]$. Results in this study showed SFN significantly suppressed the edematous paw volume produced by histamine, that is, why it may be suggested that SFN possesses anti-inflammatory activity in connection with antihistaminic property.

In the acute inflammation test, SFN showed good anti-inflammatory response by inhibiting the egg-albumin-induced rat paw edema. Subcutaneous injection of egg-albumin in the rat paw develops edema which is due to plasma extravasations, increased tissue water, and plasma protein exudation along with neutrophil extravasations [25]. The egg-albumin represents as an antigenic substance to extravascular space and is responsible for inflammation and edema. SFN effectively indicates its anti-inflammatory properties in dose-dependent manner as like standard diclofenac sodium [26].

The subchronic phase anti-inflammatory activity can be well demonstrated with cotton pellet-induced granuloma model. Characteristics of this model mainly display the monocyte infiltration, fibroblast proliferation, angiogenesis, and exudation [27,28]. The amount of granulomatous tissue formed is correlated with dry weight of cotton pellet. In this study, SFN decreased the dry weight of granuloma significantly in dose-dependent manner as compared to control groups. This may reflect the ability of SFN in reduction of number of fibroblasts, preventing angiogenesis, and synthesis of collagen and mucopolysaccharide [29]. Release of inflammatory cytokines such as IL- 6 and TNF- $\alpha$ is responsible for inflammatory activity which is attenuated by SFN.

Oxidative stress plays a very important role in pathophysiological development of inflammation. Hence, in the pathogenesis of induced inflammation, free radicals produced by macrophage, lymphocyte, and endothelial cells are responsible for various organs degeneration. However, increased lipid peroxidation and deterioration of oxidative

Table 1: Subacute anti-inflammatory activity of SFN on cotton pellet-induced granuloma model in rats

\begin{tabular}{lllll}
\hline Treatment group and dose & Wt. of exudates (mg) (Wet-Dry) & \%inhibition & Wt. of granuloma (mg) (Wet-Dry) & \%inhibition \\
\hline Group I & - & - & - & - \\
Group II & $98.16 \pm 0.49$ & - & $88.72 \pm 0.54$ & - \\
Group III & $35.67 \pm 0.77$ & 63.66 & $30.24 \pm 0.66$ & 65.91 \\
\hline
\end{tabular}

SFN: Sulforaphane

Table 2: Effect of SFN on Serum Hepatic enzymes (SGOT, SGPT, and ALP Levels) and Antioxidant Enzymes (GSH, Catalase, and SOD) on Cotton Pellet-induced granuloma model in rats

\begin{tabular}{|c|c|c|c|c|c|c|}
\hline \multirow[t]{2}{*}{ Treatment } & \multicolumn{3}{|c|}{ Serum Hepatic Enzymes } & \multicolumn{3}{|l|}{ Antioxidant Enzymes } \\
\hline & SGOT (U/ml) & SGPT (U/ml) & $\operatorname{ALP}(\mathrm{U} / \mathrm{ml})$ & GSH (U/mg protein) & Catalase (U/mg protein) & SOD (U/mg protein) \\
\hline Group I & $51.42 \pm 2.19$ & $18.56 \pm 1.69$ & $28.82 \pm 0.99$ & $8.97 \pm 0.36$ & $10.07 \pm 0.49$ & $15.17 \pm 0.43$ \\
\hline Group II & $105.10 \pm 3.70^{*}$ & $57.20 \pm 2.97 *$ & $77.53 \pm 2.76^{\#}$ & $3.04 \pm 0.13^{*}$ & $3.44 \pm 0.29^{\#}$ & $5.23 \pm 0.30^{* *}$ \\
\hline Group III & $63.57 \pm 2.29$ & $23.71 \pm 2.01$ & $50.15 \pm 1.04$ & $6.56 \pm 0.21^{*}$ & $9.56 \pm 0.30^{\#}$ & $13.61 \pm 0.38^{* *}$ \\
\hline Group IV & $82.88 \pm 2.82 *$ & $34.43 \pm 2.24^{* *}$ & $62.28 \pm 2.28^{\#}$ & $5.13 \pm 0.39 *$ & $7.49 \pm 0.38^{\#}$ & $11.92 \pm 0.32^{* *}$ \\
\hline Group V & $65.63 \pm 2.41 *$ & $27.42 \pm 2.14^{* *}$ & $52.93 \pm 1.77^{\#}$ & $9.34 \pm 0.36^{*}$ & $10.83 \pm 0.40^{\#}$ & $16.57 \pm 0.46^{* *}$ \\
\hline
\end{tabular}

SFN: Sulforaphane, SGOT: Serum glutamic oxaloacetic transaminase, SGPT: Serum glutamic pyruvic transaminase, ALP: Alkaline phosphatase, GSH: Glutathione, SOD: Superoxide dismutase 
biomarkers (GSH, catalase, and SOD) are common in diseased patients. Different literature revealed that GSH, catalase, and SOD are wellestablished biomarkers of oxidative stress [30-32]. The increased levels are indicative of antioxidative property. Furthermore, phytomolecule ITC is having high antioxidant property. Nevertheless, SFN which is chemically an ITC is having ability to decrease oxidative stress [33]. This is what reflected in our study, i.e. the toxicant-induced oxidative biomarkers are attenuated in dose-dependent administration of SFN which is higher than standard Diclofenac [34]. Serum hepatic enzyme (i.e.SGPT, SGOT, and ALP) estimation is an excellent and conventional tool in anti-inflammation drug screening process. Significant elevation of the hepatic enzymes in toxicant control rats is a clear reflection of hepatic impairment in diseased rats. In the inflammatory pathophysiology, serum hepatic enzyme plays a key role in the synthesis of inflammatory mediators like bradykinin [35]. From literature, it is indicated that there exists a positive correlation between increased serum hepatic enzyme level and the disease progression [34]. The current study reflects increment in baseline serum hepatic enzyme level in toxicant control rat. However, with dose-dependent administration of SFN, there is a significant decrement in elevated serum hepatic enzymes, which reflects simultaneously anti-inflammatory and hepatoprotective effect of SFN.

The toxicant-induced inflammation is a biphasic process. The acute phase (0-10 days) characterized by vascular exudates and responsible for edema, results due to various mediators (such as histamine, serotonin, kinins, and prostaglandins) released by leukocytes that migrate to the affected regions. The second and chronic phase (1021 days) contributes to different cellular inflammatory mediators

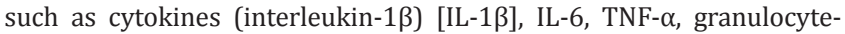
macrophage colony-stimulating factor, interferon- $\gamma$, and prostaglandin. The cytokines, i.e., both pro and anti-inflammatory cytokines, are important regulators of synovial inflammation. The potential therapeutic agent in inflammation considered those agents which are having proinflammatory cytokine suppression activity. In our study, SFN dose-dependently inhibits proinflammatory cytokines IL- 6 and TNF- $\alpha$.

\section{REFERENCES}

1. Maldini M, Sosa S, Montoro P. Screening of the topical antiinflammatory activity of the bark of Acacia cornigera Willdenow, Byrsonima crassifolia Kunth, Sweetia panamensis Yakovlev and the leaves of Sphagneticola trilobata Hitchcock. J Ethnopharmacol 2009; $122: 430-3$.

2. Vickerstaff JM, Bielory L. Type I hyper-Sensitivity: Atopic Allergy in Understanding Allergy Sensitivity and Immunity: A Comprehensive Guide. New Brunswick: Rutgers University Press; 1990. p. 126-36.

3. Kumar V, Abbas AK, Fausto N. Robbins and Cotran Pathology Basis of Disease. $7^{\text {th }}$ ed. Philadelphia: Saunders Elseviers; 2005.

4. Hossain M, Alam M, Chowhdury N. Antioxidant, analgesic and antiinflammatory activities of the herb Eclipta prostrata. J Pharmacol Toxicol 2011;6:468-80.

5. Scott DL, Wolfe F, Huizinga TW. Rheumatoid arthritis. Lancet 2010;37:104-8.

6. Goldring MB, Marcu KB. Cartilage homeostasis in health and rheumatoid diseases. Arthritis Res Ther 2009;11:224.

7. Smolen JS, Landewe R, Breedveld FC, Dougados M, Emery P, Gaujoux-Viala C, et al. EULAR recommendations for the management of rheumatoid arthritis with synthetic and biological disease-modifying anti rheumatic drugs. Ann Rheum Dis 2010;69:964-75.

8. Zhang P, Li J, Han Y, Yu XW, Qin L. Traditional Chinese medicine in the treatment of rheumatoid arthritis: A general review. Rheumatol Int 2010;30:713-8.

9. Venkatesha SH, Berman BM, Moudgil KD. Herbal medicinal products target defined biochemical and molecular mediators of inflammatory autoimmune arthritis. Bioorg Med Chem 2011;19:21-9.

10. Keisuke I, Bian BL, Li XD, Takashi S, Akira I. Action mechanisms of complementary and alternative medicine therapies for rheumatoid arthritis. Chin J Integr Med 2011;17:723-30.

11. Safari VZ, Kamau JK, Nthiga PM, Ngugi MP, Orinda G. Antipyretic, antiinflammatory and antinociceptive activities of aqueous bark extract of Acacia nilotica (L.) Delile in Albino Mice. Pain Manage Med
2016;2:113-8.

12. Soetan KO, Aiyelaagbe OO. The need for bioactivity-safety evaluation and conservation of medicinal plants. Rev J Med Plants Res 2009;3:324-8

13. Brooks JD, Paton VG, Vidanes G. Potent induction of Phase 2 enzymes in human prostate cells by sulforaphane. Cancer Epidemiol Biomarkers Prev 2001;10:949-54.

14. Clarke JD, Dashwood RH, Ho E. Multi-targeted prevention of cancer by sulforaphane. Cancer Lett 2008;269:291-304.

15. Talalay P, Fahey JW, Healy ZR, Wehage SL, Benedict AL, Min C, et al. Sulforaphane mobilizes cellular defenses that protect skin against damage by UV radiation. Proc Natl Acad Sci U S A 2007;104:17500-5.

16. Fahey JW, Talalay P. Antioxidant functions of sulforaphane: A potent inducer of phase II detoxification enzymes. Food Chem Toxicol 1999;37:973-9.

17. Ritz SA, Wan J, Diaz-Sanchez D. Sulforaphane-stimulated phase II enzyme induction inhibits cytokine production by airway epithelial cells stimulated with diesel extract. Am J Physiol Lung Cell Mol Physiol 2007;292:L33-9.

18. Veerappana A, Miyazakib S, Kadarkaraisamyc M, Ranganathana D. Acute and sub acute toxicity studies of Aegle marmelos Corr-an Indian medicinal plant. Phytomedicine 2007;14:209-15.

19. Winter CA, Risely EA, Nuss GW. Carrageenin- induced edema in the hind paw of rat as an assay for anti-inflammatory drugs. Proc Soc Exp Biol Med 1962;111:544-7.

20. Singh U, James T, Senthil KV, Sridevi D, Ishwarlal J. Development of an in vitro screening assay to test the anti-inflammatory properties of dietary supplements and pharmacologic agents. Clin Chem 2005;51:2252-6.

21. Payan DG, Shearn M. A nonsteroidal antiinflammatory drugs: Nonopioid analgesics: Drugs used in gout. In: Katzung BG, editor. Basic and Clinical Pharmacology. USA: Appleton and Lange; 1989. p. 431-50.

22. Singh S, Majumdar DK, Rehan HM. Evaluation of anti-inflammatory potential of fixed oil of Ocimum sanctum (Holybasil) and its possible mechanism of action. J Ethnopharmacol 1996;54:19-26.

23. Linardi A, Costa SK, da Silva GR, Antunes E. Involvement of kinins, mast cells and sensory neurons in the plasma exudation and paw oedema induced by staphylococcal enterotoxin B in the mouse. Eur J Pharmacol 2000;399:235-42.

24. Cuman RK, Bersani-Amadio LA, Fortes ZB. Influence of type 2 diabetes on the inflammatory response in rat. Inflamm Res 2001;50:460-5.

25. Yankanchi SR, Koli SA. Anti-inflammatory and analgesic activity of mature leaves of methanol extract of Clerodendrum inerme L. (Gaertn). J Pharm Sci Res 2010;11:782-785

26. Perianayagam JB. Studies on anti-inflammatory activity of crude aqueous extract of clerodendron fragrans in experimental animals. Int $\mathrm{J}$ Pharm Sci 2012;2:32-6.

27. Vogel HG. Drug Discovery and Evaluation. Pharmacological Assay.

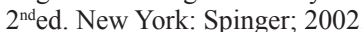

28. Majno G. Chronic inflammation: Links with angiogenesis and wound healing. Am J Pathol 1998;153:1035-9.

29. Babu PN, Pandikumar P, Ignacimuthu S. Anti-inflammatory activity of Albizia lebbeck Benth, an anthomedicinal plant, in acute and chronic models of inflammation. J Ethnopharmacol 2009;125:356-60.

30. Gelderman KA, Hultqvist M, Olsson LM, Bauer K, Pizzolla A, Olofsson P, et al. Rheumatoid arthritis: The role of reactive oxygen species in disease development and therapeutic strategies. Antioxid Redox Signal 2007;9:1541-67.

31. Pany SK, Pal A, Sahu PK. In silico analysis of cyclooxygenase inhibitory activity of some natural molecules. Int J Pharm Pharm Sci 2013;5:410-2.

32. Panda P, Pal A, Maharana L, Ghosh G. Antibacterial and antioxidant activities of methanolic extract of Bauhinia racemosa. Int J Pharm Pharm Sci 2016;8:277-81.

33. Kolm RH, Danielson UH, Zhang Y, Talalay P, Mannervik B. Isothiocyanates as substrates for human glutathione transferases. Biochem J 1995;311:453-9.

34. Adeneye AA, Oreagba AI, Ishola IO, Kalejaiye HA. Evaluation of the anti-arthritic activity of the hydroethanolic leaf extract of alchornea cordifolia in rats. Afr J Tradit Complement Altern Med 2014;11:402-10.

35. Glenn B, Gray JD, Kooyers W. Chemical changes in adjuvant induced polyarthritis of rats. Ann J Ven Res 1965;26:1195-203.

36. Niino NY, Akama H, Hara M. Alkaline phosphatase (ALP) activity in rheumatoid arthritis-its clinical significance and synthesis of ALP in RA synovium. Ryumachi 1998;38:581-8. 